Check for updates

Bogotá

Cite this as: $B M J 2022 ; 376: 0519$

http://dx.doi.org/10.1136/bmj.0519

Published: 28 February 2022

\title{
Covid-19: Lagging vaccination leaves the Caribbean vulnerable, says PAHO
}

Luke Taylor

The sluggish pace of covid-19 vaccination in the Caribbean is leaving the region vulnerable to current and future outbreaks of the disease, senior Pan American Health Organization (PAHO) officials have warned. ${ }^{1}$

Unlike much of Latin America, where vaccination campaigns started slowly but ramped up quickly through 2021 when more doses became available, vaccination coverage across the Caribbean remains low. Of the 13 countries in the Americas that are yet to reach the World Health Organization's 2021 goal of $40 \%$ vaccination coverage, 10 are in the Caribbean.

Only regional outliers Cuba-which produces its own vaccines-and the Dominican Republic have fully vaccinated more than half of their population. Haiti, which has been hit by natural disasters and political turmoil, has fully vaccinated less than $1 \%$ of its citizens against covid-19.

Though the number of new infections reported in the Caribbean last week fell by $44 \%$, eight countries reported an increase in deaths. The region has now recorded more than 3.1 million covid-19 infections and 31600 deaths. $^{2}$

Healthcare workers, a substantial number of whom are unvaccinated, remain particularly vulnerable, said PAHO director Carissa Etienne. "These are legitimate questions that must be acknowledged and addressed so that we can better protect our healthcare workers and everyone else," she said.

A lack of vaccination centres in remote areas, healthcare staff, and cold chain infrastructure are holding back vaccination in the Caribbean, said senior PAHO officials. They called for governments to ensure that vaccination centres are closer to the people who need them most and that they are open at times convenient for those that work.

Some South American nations that are currently rolling out booster doses for covid-19, such as Colombia, are sending vaccines to Caribbean nations, including the Bahamas, through PAHO's Revolving Fund to accelerate their immunisation campaigns. ${ }^{3}$

Though access to vaccines is increasing, misinformation is deterring people from getting jabbed. Alfonso J Rodríguez-Morales, president of the Colombian Association of Infectious Diseases, has studied covid-19 vaccination willingness in Latin America and the Caribbean. ${ }^{4}$ He said that claims that vaccines are unsafe are rife in the Caribbean and spread primarily by "influencers" through social media. Some false claims have even been made by local doctors. "Misinformation has led to fears and non-evidence based doubts regarding the efficacy and safety of approved, well known and studied vaccines that we have already been using for more than a year," Rodríguez-Morales said.

A lack of trust in governments and public health authorities in the Caribbean means that people are more likely to believe that vaccines are dangerous or unsafe. Such claims were already circulating in 2020 before vaccines were available, said Joy St John, executive director of the Caribbean Public Health Agency in Trinidad and Tobago.

"Caribbean groups are spreading vaccine disinformation and are targeting several sections and sectors of society through inter-weaving relevant or familiar cultural references," she says. "It has been the most organised and relentless campaign I have witnessed in more than 30 years as a doctor." PAHO's Etienne urged Caribbean nations to work with community leaders and trusted public figures to tackle concerns around vaccination and combat misinformation.

Though vaccine hesitancy is high in the Eastern Caribbean, people there are open to changing their minds once they are better informed, a survey by PAHO and Unicef found. Just over half (51\%) of people who said they were apprehensive about getting jabbed were open to changing their minds after seeing more scientific and medical evidence to support vaccination. ${ }^{1}$

Education and instilling trust in the vaccines are essential to protect the region against the highly infectious omicron variant and future variants that might evolve, Etienne said. "We have the power as a community to overcome these barriers and reduce the toll of this virus on our people," she said.

\footnotetext{
Pan American Health Organization. Low vaccination rates in the Caribbean must be urgently addressed to stop the spread of covid-19 says PAHO director. https://www.paho.org/en/news/23-2-2022-low-vaccination-ratescaribbean-must-be-urgently-addressed-stop-spread-covid-19-says

2 Reliefweb. Covid-19 Latin America and the Caribbean.,https://reliefweb.int/topics/covid-19-latin-america-and-caribbean

3 Pan American Health Organization. The Bahamas receives covid-19 vaccines through a collaboration between PAHO/WHO, Canada, and Colombia. https://www.paho.org/en/news/28-12-2021-bahamas-receives-covid-19vaccines-through-collaboration-between-pahowho-canada-and

4 Rodriguez-Morales AJ, Franco OH. Public trust, misinformation and COVID-19 vaccination willingness in Latin America and the Caribbean: today's key challenges. Lancet Reg Health Am 2021;3:100073. doi: 10.1016/j.lana.2021.100073 pmid: 34522914

This article is made freely available for personal use in accordance with BMJ's website terms and conditions for the duration of the covid-19 pandemic or unti otherwise determined by BMJ. You may download and print the article for any lawful, non-commercial purpose (including text and data mining) provided that all copyright notices and trade marks are retained.
} 